\title{
INTRODUCTION
}

\section{Exploring the Lived Experiences of Our Students}

How well do we know our students? We might justifiably pride ourselves in being student-oriented, and we may be skilled at building rapport with our students, but this isn't necessarily tantamount to really knowing them. What is it like to truly grapple with the work we ask them to do? It all might seem quite reasonable to us, but the students' experiences could be quite different.

These questions and considerations have been brought front and center for us as we read the papers that constitute this issue of Teaching \& Learning Inquiry. Many of these papers, each in its own way, attempts to better understand the lived experiences of our students. Nathan Webb and Laura Obrycki Barrett take a detailed look at just how we get to know students who are learning English as a second language. The key processes they identify-including such behaviors as being uncommonly attentive, establishing common grounding, and forming connections — can be applied to all teaching.

Mary Goldschmidt explores students' lived experiences as disciplinary learners of both content and process, which includes learning to write the genres and conventions of their chosen fields. She foregrounds the rich descriptions of a few seniors who've developed "their own 'place within the disciplinary enterprise" (p. 27).

Jonathan Cisco has created a more effective way of teaching students how to write literature reviews based on his direct observations of the struggles they were going through with such assignments. Interviews indicated that students were at a loss regarding the best approach to writing a literature review - much less, what a good review accomplished. Yet such reviews are among the most common assignments we require.

Shane Dawson and Harry Hubball use computer-based analytics to chart the actual paths students take as they navigate their way through academic programs. This analysis yields very useful insights regarding students' perceptions of relationships among courses, as well as challenges students face simply piecing together that which we require of them.

Michael Drinkwater, Deanne Gannaway, Karen Sheppard, Matthew Davis, Margaret Wegener, Warwick Bowen, and Joel Corney take us inside the physics classroom to better understand that lived experience. We are moving well beyond the student-as-passivevessel model in large classes, challenging students to engage with problems and issues in these settings. This team from the University of Queensland has shown that the value of the time spent in such active classrooms is affected considerably by the degree of preparation students bring into them. They present a strategy that is manageable and yet ensures that students arrive prepared. Moreover, the approach gives the instructor impor- 
tant information about where the difficulties and misconceptions lie, even before he has begun to teach that class.

To truly understand the students' lived experiences, we must delve into just what they think learning entails in the first place. Deborah Roberts-Harris came to the conclusion that the pre-service science teachers she was working with needed to have a clear understanding of what it should mean to learn science-not just to memorize science. Roberts-Harris found evidence of the development of this understanding in the planning and teaching these students did.

And speaking of "evidence," what evidence will help us make visible our students' lived experiences? Much discussion has taken place within the field of SoTL regarding the privileging of some forms of evidence over others. Kirthi Premadasa's impressions of this year's SoTL Commons conference describes a keynote by Nancy Chick in which she encourages us to expand the range of evidence of student learning we value. This is a topic we think about a great deal as we edit TLI. Regan Gurung argues that, rather than debate what evidence should be privileged, we should expand repertoires of evidence by learning more about what each has to offer: we need to learn from differences, not be put off by them. As editors, we would heartily agree and hope the pages of TLI continue to showcase this range.

According to Chng Huang Hoon, learning from differences is a significant theme in Tinberg and Weisberger's book, Teaching, Learning, and the Holocaust: An Integrative Approach. Chng finds inspiration in the experiences of both instructors and students. She observes that:

the teachers and students accepted a challenge in pedagogy to unlearn and relearn what everyone has taken for granted in viewing, teaching, and learning a subject from one perspective; walked in another person's (disciplinary) shoes to develop empathy for another point of view; and emerged with an enriched student's - and I hasten to add-and teacher's understanding of a traumatic catastrophic event in human history.

This is where we can go when we strive to better understand the students' lived experiences. We hope this issue of Teaching \& Learning Inquiry will help you along that journey.

Gary Poole is the Associate Director of the School of Population and Public Health and a Senior Scholar in the Centre for Health Education Scholarship at the University of British Columbia.

Nancy Chick is Assistant Director of the Center for Teaching and an affiliated faculty member in the English Department at Vanderbilt University. 